\title{
RESPONSABILIDADE SEM CULPA
}

\author{
Álvaro Ferreira da Costa \\ Professor da Faculdade de Direito do Ceará
}

1 - A responsabilidade civil, ou a obrigação de reparar o dano, supõe o encontro de dois interêsses, num conflito de que resulta, pelo menos, o sacrifício de um dêles. Acontece, às vêzes, que êsse encontro de interêsses está previsto e é objeto de regulação convencional, expressa ou não; outras vêzes o conflito dáse acidentalmente, sem que os interêssados tenham regulado, explícita ou implicitamente, a maneira de compôr o dano. Chamase de responsabilidade contratual aquela que se regulamenta segundo o contrato; extra-contratual, ou aquiliana, nos demais casos. Essa maneira de colocar o problema tem um valor puramente esquemático; será um conceito provisório, que nos permitirá ingresso no assunto através da consideração mais geral possível.

As observações que se seguem visam ùnicamente a êsse último aspecto da responsabilidade civil; devo restringir ainda mais o objeto, dizendo que tratarei apenas de um sub-aspecto da questão, que é o da responsabilidade extracontratual sem culpa.

2 - As soluções dadas ao problema da responsabilidade civil resultam de duas tendências fundamentais do sentimento de justiça: a primeira é a exigência de estabelecer-se o equilíbrio das reações econômicas jurídicas alteradas pelo dano; a segunda é que todo indivíduo deve ser o garante de seus atos e de suas consequências. Estas duas tendências se realizam jurìdicamente em dois princípios: um é que a qualquer dano deve 
corresponder uma reparação; outro diz quem deve fazer essa reparação. Nosso Código pretende conceber de forma unitária essas duas idéias, dizendo que todo dano merece reparação e o responsável é aquêle que o causar. Ajunta-se que essa responsabilidade supõe uma vontade, direta (ação ou omissão voluntária) ou indireta (negligência, imprudência ou imperícia). A responsabilidade civil extracontratual está subordinada, nessas condições, a uma dupla causalidade; a causalidade pròpriamente dita, objetiva, que se estabelece entre o fato e o dano, a a causalidade subjetiva, ou imputabilidade, que deve existir entre a vontade e o fato. $O$ esquema da responsabilidade civil pode ser representado por uma corrente causal, cujo primeiro elo é a-vontade do agente ofensor, o segundo é o fato danoso e o terceiro é o próprio dano.

Nosso direito civil, portanto, quer realizar aquelas duas tendências do sentimento de justiça sob uma forma unitária, mas corre o risco de não tornar efetivas quer a primeira, quer a segunda, pois, na verdade, nem todo dano é efetivamente indenizável, nem todo culpado se torna realmente responsável: ou porque o agente seja insolvável, ou porque nã̉o seja encontrado em culpa, ou porque não possa esta ser demonstrada. De tal modo, a construção técnico-legal do princípio da responsabilidade, abrangendo duas idéias até certo ponto inconciliáveis, acaba por deixar à margem de qualquer reparação um grande número de direitos ofendidos: a vítima está numa situação de inferioridade diante do ofensor e resta um mundo de interêsses legítimos insusceptível de proteção jurídica. Na verdade, o que vai tornar reparável o dano, no rigor da doutrina clássica, não é jamais a condição a que se vê reduzido o ofendido, mas a inexcusabilidade do autor da ofensa. Assim, o subjetivismo, em matéria de responsabilidade civil, consiste em fazer prevalecer, sôbre o interêsse social de restabelecer o equilíbrio rompido pelo dano, a idéia de responsabilizar $o$ autor dêste sòmente quando fôr encontrado em culpa.

Impõe-se, destarte, um esfôrço do jurista, no sentido de conferir melhor ajuda às situações desprotegidas. Então, o in- 
vestigador se defronta logo com uma escolha: ou adere a essa hipertrofia do subjetivismo, ou corrije-lhe os excessos, ou submete o princípio da responsabilidade civil às dominâncias do sentimento objetivista, ou despreza a construção unitária do princípio, estabelecendo regras autônomas relativas a cada ordem de idéias.

3 - Agora, é o instante de examinar em que consiste,fundamentalmente, a responsabilidade subjetiva. Acreditamos que ela se fundamenta em duas ordens de idéias.

A primeira consiste na valorização da vontade humana, que é ainda verdadeiro dogma do direito privado contemporâneo, e segundo o qual, fora dos casos legais, só a vontade humana é legítima criadora de direitos e geradora de obrigações. É o respeito à vontade que impede o ressarcimento quando aquêle que estaria obrigado a fazer a reparação não quís o dano, ou não pôde impedí-lo. A vontade é, desta forma, cousa sagrada ao direito; violentá-la seria o mesmo que ofender a liberdade ou personalidade. Repugnaria, portanto, ao senso moral da coletividade obrigar à reparação aquêle que, tendo causado ofensa ao direito alheio, procedeu de forma irreprovada. Não se pode, legìtimamente, deixar de conferir à vontade humana um valor próprio, a que o direito deve proteção e reconhecimento. Essa dignificação da pessoa humana e da vontade é, certamente, o resultado dum progresso das idéias jurídicas. 0 que falta, porém, é a valorização adequada dessa vontade, que está a reclamar uma análise científica. Em outras palavras, o problema consiste em saber se devemos conferir a essa vontade um valor psicológico, ou um valor estritamente jurídico.

4 - Julgamos esclarecer melhor o espírito de nossas indagações, estabelecendo a questão de saber em que consiste a vontade. Entendemos, em primeiro lugar, que a vontade, é fato psicológico; mas, ao lado desse aspecto, há uma vontade jurídica. É preciso, nessas condições, ter em vista que a vontade a que se concede a aptidão criadora de direitos e geradora de obrigações não é senão a vontade jurídica. Então, como diferençar uma da outra? 
O mecanismo da vontade psicológica nos parece resumirse em vários momentos, todos subjetivos. Primeiro, é uma impressão de carência, em seguida um desêjo de suprí-la, depois é a escolha de um bem, logo mais a intenção de obtê-lo, e, afinal, a deliberação do ato. Aí termina o processo da vontade psicológica. Mas essa vontade, quando se exterioriza objetivamente no ato, é que é a vontade jurídica, a que se dão efeitos jurídicos, criadores de direitos ou geradores de obrigações. Queremos dizer que o direito é estranho àquele processo subjetivo da vontade, recebendo-a tal qual vem do mundo interior, atendendo-se sòmente às suas manifestações exteriores, ligadas indissolùvelmente ao ato. Em suma, a vontade jurídica é a que se revela no ato, nêle se manifesta, não sendo lícito cindir êsse ato, para investigar sòmente aquêle processo interno, como se fôra independente, e o qual, na verdade, é estranho à disciplina jurídica.

Se se atende a essa distinção, que não é mera questão de palavras, logo se percebe o ponto de vista em que nos colocamos: a descoberta da vontade, para os subjetivistas, é a pesquisa de uma intenção, ou seja um momento interno da vontade psicológica; para nós, a vontade descobre-se no próprio ato. $\mathrm{Pa}$ ra os subjetivistas a vontade é um fato passado, um antecedente do ato; para nós, ainda que não possamos desconhecer essa vontade psicológica, o que se deve considerar, entretanto, é a vontade jurídica, que é um fato presente, que se perpetua e vive no ato que a realiza. Os objetivistas não podem atinar que estão transportando, no meu modo de ver as cousas, as concepções religiosas para o mundo do direito. Não podemos recusar a contribuição preponderante dos princípios religiosos na moralização dos sentimentos de justiça, porém é forçoso reconhecer que os princípios religiosos, concedendo sanções que afetam apenas o íntimo das pessoas, sòmente haveriam de considerar, lógicamente, os momentos internos da vontade. $\mathrm{O}$ direito, que tem por missão cuidar de sanções objetivas e exteriores, haverá de considerar, consequentemente, não a vontade psicológica, mas a vontade jurídica. Parece-nos, portanto, haver um equívoco ruinoso na fundamentação da responsabilidade civil com respeito à vontade. É que se foge de distinguir entre a vontade psicológi- 
ca e a vontade jurídica, dando-se à responsabilidade jurídica 0 mesmo fundamento religioso: o pecado. $O$ que nos cumpre, ao contrário, é considerar o ato, não em função de suas geratrizes psicológicas, mas na sua existência consubstanciada no ato. É o que se poderia chamar de ativismo jurídico, por oposição ao voluntarismo psicológico. A consequência mais importante dêsse restabelecimento da vontade, na posição que lhe compete nas considerações jurídicas, seria, como já teremos percebido, a da objetivação da noção de culpa, cuja prova não competirá mais à vítima, cabendo ao agente demonstrar a inexistência dela. É que não é lícito presumir uma vontade cindida no momento de exteriorizar-se; se ocorre êsse processo de separação, ao agente cumpre esclarecê-la; e nisso é que haverá a demonstração da inexistência de culpa. Não cause estranheza essa maneira de ver, porque já o direito penal se antecipa na consagração dessas idéias: com efeito, ainda que a existência do crime dependa da voluntariedade (em sentido lato) da ação, o simples matar alguém tráz, implícita, a noção da culpa, salvo ao homicida alguma dirimente ou justificativa. De qualquer modo, a isenção de culpa, por isso que resulta de uma cisão improvável entre o ato e a vontade, há de ser demonstrada pelo agente.

5 - Uma segunda ordem de idéias tem influído consideràvelmente para a permanência dessa entronização do princípio da culpa como fundamento da responsabilidade civil. Parece aos partidários do subjetivismo que ofende ao senso comum da justiça onerar-se alguém que, embora causando dano a direito alheio, procedeu contudo de modo a não se lhe poder irrogar culpa demonstrada. É essa, sem dúvida, antiga idéia moral, fundada em mal entendida presunção de boa fé nos atos humanos, mas que empalidece nos dias em que vivemos. Admitimos que a moral tenha um valor absoluto; mas, é incontestável, não o têm as formas da moralidade, as quais participam do senso mutável da coletividade. Quando se exige a culpa como pressuposto ou condição da imputabilidade, o que se pratica, na verdade, é uma visão unilateral das cousas, porque se considera a situação do ofensor, mas não também a da vítima. Demais disso, se é injusto onerar-se quem não se demonstra estar em culpa, que se pode 
dizer dessa aberração de equidade, que manda carregar os prejuízos à conta da vítima sabidamente inocente?

O que a percepção humana das cousas aconselha, como regra moral, não pode ser a irresponsabilidade. Nisto se conjugam o sentimento moral, que se recusa a desprezar a situação da vítima inocente; a regra jurídica, que não concebe normalmente a possibilidade de um procedimento irrepreensível causar dano; e as idéias sociais, que acodem pressurosas em proteger os fracos, os pobres e as vítimas. A desatenção ao direito das vítimas é tanto mais clamorosa quanto, aumentando-se com o progresso industrial os benefícios, a distribuição dos valores positivos, que dêles resultam, cabe a uns poucos; mas êsses benefícios de poucos não podem ser utilizados sem um risco cada vez mais intenso, numa série de ônus indiscriminados e indeterminados, que vão pesar sôbre a imensa maioria dos desfavorecidos. Do ponto de vista da técnica jurídica observa-se então que, no conflito entre duas tendências, formadas, de um lado pelo interêsse de reparar o dano, e de outro lado, pelo sentimento de que só o culpado deve a reparação, - observa-se que êsse último se hipertrofia, a ponto de absorver, nulificando-o, o primeiro. $\mathrm{O}$ subjetivismo jurídico conduz, portanto, à negação mesma dos princípios em que se funda a responsabilidade civil, que seria 0 justo equilíbrio entre as duas tendências opostas: o interêsse de reparar o dano e o de sujeitar à reparação o que lhe tiver dado causa. Porque, na verdade, a consagração técnico-legal da responsabilidade civil se estabelece, na prática, pela desatenção mais completa ao interêsse social de reparar o dano e atêm-se ùnicamente ao princípio da culpa como fundamento da reparação.

6 - 0 sentimento jurídico, de um lado, e de outro as idéias morais e sociais, provocaram, desde fins do século passado, uma reação salutar contra o subjetivismo na responsabilidade civil, que ameaça ir aos extremos de subverter completamente os princípios dominantes. Essa reação acabou por introduzir no sistema da responsabilidade elementos do causalismo ou subjetivismo jurídicos, como melhor se verá do ligeiro retrospecto histórico da evolução da responsabilidade civil. 
Se se pusesse, há um século, dizia Marc Ancel, nas Jornadas de Direito Civil de Zurich, a questão da responsabilidade sem culpa, estaríamos arriscados a não ser entendidos, ou se provocaria com o simples enunciado do problema "un étonnement un peu scandalisé". Pelo contrário, 50 anos mais tarde, um aresto da Câmara da Côrte de Cassação, amorçant a jurisprudência construtiva sôbre a responsabilidade das cousas inanimadas, fazia aparecer o problema sob um novo ângulo, suscitando comentários apaixonados. Tratava-se de um operário ferido pela explosão de uma caldeira; mas a responsabilidade do patrão, regulada pelo art. 1382 do C. C. francês, exigia a prova de uma culpa imputável ao empregador. Não obstante, a Côrte de Cassação admitiu nesse caso a responsabilidade do patrão, fundada em que, segundo o art. 1384, a responsabilidade decorrerá apenas do dano que se causa por fato próprio, mas ainda do que é causado por fato de cousas de que se tem a guarda. 0 célebre aresto de 1896 dava satisfação, torcendo o texto legal, a um sentimento de eqüidade, que, dois anos mais tarde, adquiria expressão legal e onde se manifestavam todo os elementos que iam pôr em cheque as concepções tradicionais. Em primeiro lugar, o inopinado do fato não podia ter uma causalidade determinada; depois, como situar o elo culpado na complicada hierarquia da emprêsa? Afinal, era um acidente produzido pela máquina, num mundo em que o desenvolvimento industrial intensificava e multiplicava os danos. Por outro lado, a condição do trabalhador merecia atenção particular. Como restabelecer o equilíbrio das relações jurídicas rompido com o dano? Que seria mais justo: acrescentar à infelicidade da vítima a sobrecarga dos prejuizos ou amenizar-lhe o ônus, atribuindo uma parte dêle a quem tirava proveito da máquina? A resposta a essas questões vai de parelhas com a simples proposição delas. Desta maneira, a lei mesma é que se encarrega de abrir uma grande brecha no sistema da responsabilidade subjetiva; e, quebrada a inteireza do sistema, o embate contra a doutrina tradicional se reforça com os subsídios da antiga prática do direito comercial, ou dos progressos do direito administrativo, escapando à célebre antinomia entre soberania e responsabilidades, ou dos novos desenvolvimentos da teoria das obrigações, pela desperso- 
nalização do vínculo obrigatório e pela definição da obrigação como elemento ativo ou passivo do patrimônio.

Enfim, as tendências socializadoras do direito civil ameaçam subverter por completo as noções tradicionais. Começa-se a esboçar um movimento no sentido da socialização contra acidentes, nas relações do trabalho ou nas relações puramente civis de qualquer ordem, seja na criação, pelo Estado, de fundos especiais de garantia, destinados a compor os danos sofridos pelas vítimas. Chama-se a isso de um fenômeno de materialização do direito civil, o abandono das noções morais na vida jurídica; na verdade, é uma nova moralidade que se esboça, são novas formas de espiritualidade, que têm advento na vida social.

7 - Quais serão, então, as tendências hodiernas em matéria de resposabilidade civil? Será que a teoria da culpa tende a desaparecer, dando lugar a uma concepção inteiramente objetiva? Será mesmo justificável, em face do sentimento geral, essa subversão de princípios? Para sermos realistas, é forçoso reconhecer que o direito moderno se encaminha no sentido de um sistema ainda que não exclusivo, mas subsidiário, fundado na responsabilidade sem culpa. Mas, ao lado disso, duas tendências se evidenciam. Lapaulle resume admiràvelmente êsses movimentos de idéias, dizendo: $10^{\circ}$ - responsabilidade sem culpa, para ressaltar o caráter sagrado de certos direitos. E exemplifica: quando penetramos na propriedade privada de alguém, invadindo-a, pouco importa que estejamos ou não em falta; somos responsáveis pelo dano que então causarmos e isto ùnicamente para sancionar, em um caso dado, o caráter eminentemente sagrado de certos direitos. $2^{\circ}$ - a distinção dos riscos: o risco de ter sob guarda um instrumento perigoso, ou não. É-se responsável quando se tem a guarda de um touro, mas não quando um beija-flor, que escapa, vai ferir o ôlho de alguém. É-se responsável quando se mantém uma caldeira com água em ebulição, porque a caldeira possui um dinamismo intrínseco; mas já não haverá responsabilidade, quando se trata de um poço ou uma cacimba e uma fissura aberta no mesmo venha causar uma inundação e incomodar terceiros: porque a água do poço, nor- 
malmente, não oferece perigo de dano. Conseqüentemente, conclui Lapualle, nem teoria do risco, nem idéia de culpa, mas de um perigo conhecido da pessoa que detém uma cousa ou pratica atividade causadora de risco. Há, porém, uma terceira direção do pensamento jurídico, que consiste em não admitir qualquer oposição entre a teoria do risco e a da culpa. Esta não seria, com efeito, senão parte integrante, e perfeitamente legítima, de uma concepção mais vasta, que, ou reduz as duas formas a uma, as duas formas a um só tipo ou constrói duas formas ou modalidades de responsabilidade civil, uma subsidiária, completando a outra. Fóra dos casos da responsabilidade culposa, era ou seria o caso de indagar: ocorrido o dano, sem que se possa demonstrar a culpa do ofensor, e sendo a vítima inocente, deve esta suportar inteiramente o prejuízo? Trata-se de ver, no conjunto da situação social, qual será a melhor solução. 0 caso típico é o do acidente no trabalho. Quem deve suportar o risco? Considera-se que, na realidade, é preferível que o empregador suporte o dano causado pelo acidente. Demais disso, sempre tenho em vista a condição social dos patrimônios que se encontram, considera-se que aquêle que fôr encontrado em culpa deve normalmente suportar os danos, porque a segurança dinâmica impõe a todos os indivíduos uma conduta da mais rigorosa prudência. Tratar-se-ia, portanto, de uma responsabilidade com culpa, integrada em um sistema mais vasto. Mas essa responsabilidade evidentemente, não pode ter uma indenização unitária, como é o caso do art. 159 do nosso Cod. Civil. Haveria de descobrir, como o fêz a jurisprudência francêsa, um princípio de responsabilidade no art. 1982 e outro no art. 1384. É uma regra genérica, correspondente ao art. 1382 do Cod. Civil francês, que está faltando a nosso direito civil.

8 - Nosso direito civil é, e com êle a jurisprudência, particularmente alérgico à consagração da teoria do risco. A tese dominante e absorvente é a da responsabilidade subjetiva, salvo concessões especialíssimas, que não chegam a formar cousa pacífica em nosso direito positivo. Na doutrina, porém, o esfôrço no sentido da objetivação da responsabilidade ganha a cada dia maior terreno: uns defendem abertamente a teoria causal em 
tôda a sua inteireza, outros a admitem como exceção expressa à teoria da culpa. À legislação cabe, sem dúvida, a realização eficaz; mas a sua adesão à responsabilidade objetiva limita-se a uns poucos diplomas legislativos, tais a lei n. 2681, de 1912, que regulamentou a responsabilidade das emprêsas de estradas de ferro, a lei sôbre acidentes no trabalho, o Código de Menores e o Código do Ar. Quanto ao nosso Código Civil, encontram-se, aqui e ali, disposições dispersas, que seriam uma concessão ao princípio da objetividade, sob a máscara de presunções legais de culpa. $O$ que nos interessa assinalar, entretanto, é que há um momento em que o nosso direito civil codificado adere abertamente à responsabilidade causal; e então nos ocorre perguntar se não será lícito ao intérprete, ou ao juiz, estender essa noção de responsabilidade objetiva a casos outros, de modo a inserir, no direito positivo brasileiro, mediante os processos técnicos da construção jurídica, o princípio da reparação do dano independente de culpa, como expressão subsidiária da responsabilidade civil.

Pensamos que o nosso Código Civil consagrou, em certo ponto, livre de discussões, a responsabilidade objetiva. Com efeito, supomos que não será razoável objetar contra a ressarcibilidade do dano causado em estado de necessidade. 0 art. 1519 não deixa margem a dúvidas: "se o dono da coisa, no caso do art. 160, n. II, não fôr culpado do perigo, assiste-lhe direito a indenização do prejuízo que sofreu". Quem deverá essa reparação? A lei não o diz, mas, evidentemente , o direito ao ressarcimento deve ser exercido contra o autor do dano. Estará êsse, acaso, em culpa? $\mathrm{O}$ art. 160 responde desenganadamente que não; porque, expressamente, coloca fora de qualquer ilicitude o ato pelo qual se destrói cousa alheia, afim de remover perigo iminente, contanto que a deterioração ou a destruição não exceda o limite indispensável para a remoção do perigo. Eis, portanto, um caso, para nós, indiscutível, da responsabilidade sem culpa. Então, resta perguntar se não é lícito ao intérprete, ou ao juiz, generalizar a regra para estendê-la a casos não previstos, segundo os processos técnicos de interpretação e de construção científica do direito. 
9 - Já se observou, e por certo que com tôda procedência, o necessário paralelismo no desenvolvimento das ciências entre si. A um progresso das ciências físicas corresponde, via de regra, um progresso das ciências morais. a ciência, com efeito, é uma; é o omnia scibilia dos antigos. De tal modo, o espírito que realiza progressos em um setor é o mesmo que o cria em outro. Ora, vamos encontrar um exemplo dêsse paralelismo entre as ciências físicas e a sociologia, o direito em particular, na crença, que marca, no dizer dos entendidos, o alvorecer dos tempos contemporâneos. Tal é que, para a física moderna, a crença da continuidade da matéria cedeu lugar à da sua descontinuidade. Ao mesmo tempo, no mundo da sociologia, e, particularmente, no mundo do direito, onde se gera a convicção arraigada da contiunidade do espaço jurídico, uma revolução de importantes consequências se operou. Supunha-se que o direito, uma vez codificado, abrangia a totalidade das relações sociais; ou, em outras palavras, o direito, como tegumento de proteção social, aderia ajustadamente à superfície móvel de tôda a coletividade. Hoje, porém, essa convicção é desaparecida. Observa-se, de um lado, que a superfície social possúi ondulações e anfratuosidades que a rigidez e a imobilidade da regra legal não pode acompanhar pari passu. Então, êsse mundo que o direito não ilumina desenvolve-se desordenadamente, reclamando a adesão da regra, como a planta que, privada de sol, se inclina, defeituandose, em busca do aliamento generoso da luz. Nesses casos, o juiz é chamado a prover à dissemetria e então faz-se, não o servo mas o senhor da lei, invocando princípios como o da boa fé, o do enriquecimento indevido, o da imprevisão, que os Códigos muita vez não consagram na sua generalidade, mas que funcionam como órgãos respiratórios do organismo sócio-jurídico ou como amortecedores dos choques provenientes daquela dissemetria. Aqui bastará, talvez, o recurso à interpretação fundada na analogia ou nos princípios gerais de direito. Vêzes há, porém, em que não ocorre simplesmente a inaderência normal da regra aos fatos. A discontinuidade do mundo jurídico oferece o vazio para certas existências sociais. Não basta, então, a simples interpretação. 0 jurisconsulto há de ser, nesse caso, o construtor do direito: ou realiza êle qróprio a obra de construção, em harmo- 
nia com o sistema dominante, ou a realidade desprotegida se rebelará, criando por si própria, livre das restrições impostas pela harmonia, regras à sua auto-disciplina. É a verdadeira revolução dos fatos, não só contra os Códigos, mas contra tôdas as leis e tôda forma de regulação racional. É por isso que convém à jurisprudência o adiantar-se às previsões da sociologia e realizar, de um lado, a adaptação da regra à realidade, ou, quando aquela faltar, criar originàriamente norma, como se fôra legislador

10 - 0 processo da construção jurídica, destinada a realizar o direito onde falta a regra legal, é meio consagrado imemorialmente pela ciência. A princípio, restrita àqueles países de legislação fragmentária e não codificada, onde o direito comum parecia exigir para sua integração e completo desenvolvimento uma série completa de construções teóricas, o processo construtivo ressentia-se de um apriorismo que se embasava inteiro em dados lógicos e racionais. Faltava-lhe o apôio dos fatos, a consideração sociológica, o condicionamento da realidade. Não se lhe podia negar, entretanto, o caráter de indispensabilidade: onde falta a codificação, onde a legislação é fragmentária, onde o costume é a fonte principal do direito, os progressos da realidade e a transformação da superfície social geram constantes é forçoso o recurso à criação de normas sob a fórma de princípios, desajustamentos que a tradição não pode resolver. Então, que abrangem o maior número de casos concretos. A discontinuidade do mundo jurídico gerava, indispensàvelmente, a necessidade das construções teóricas, que naquela descontinuidade encontrava justificativa e legitimação. Mas quando também se vê que o descontínuo do tecido das normas não é resultado sòmente da falta de codificação; quando se opera aquela crença universal da descontinuidade do direito legal, o processo da construção jurídica se impõe ao magistrado como ao jurisconsulto, para completar a disciplina, que a lei realiza de maneira insuficiente. Parece-nos que sòmente três condições há a atender, quando ocorrerem os pressupostos dessa criação: a primeira é de natureza formal e consiste em desenvolvê-la à margem, ou subsidiàriamente às regras vigentes; a segunda é de nature- 
za material e consiste e mser uma resposta aos apêlos da realidade, em que deve apoiar-se, nunca o produto de elocubrações inteiramente racionalistas; a terceira é que tenha um caráter de generalidade, para que a criação tenha a mesma índole moral da lei e não se torne jamais instrumento de privilégio, nem seja anárquica ou despótica.

Dado o pressuposto, que é a desconformidade entre o regime jurídico, e as condições acima enumeradas, é preciso considerar, em primeiro lugar, se o nosso direito está a exigir, em matéria de responsabilidade civil, a realização de um processo construtivo. Quer-se saber, em outras palavras, se existe desconformidade entre a vida ativa e a disciplina legal. Ora, essa desconformidade nos parece evidente. São indícios fortes dela os movimentos da opinião pública e as idéias sociais a reclamar constantemente um melhor tratamento aos pobres, aos fracos, e às vítimas. Mais significativo é o movimento legislativo, principalmente em matéria de acidentes no trabalho, em que se superaram talvez demasiadamente as exigências da objetividade. A análise social, de seu lado, confirma o desajustamento e a dissemetria. Em tôda verdade, a regra da indenizabilidade tornou-se exceção. Em todos os dias e a tôdas as horas, na vida das ruas ou no recesso dos lares, há o infortúnio do dano a pesar sôbre a vítima inocente, sem a possibilidade de reparação. A observação social e as idéias e sentimentos populares atestam, a nosso ver flagrantemente, essa clamorosa dissemetria entre o direito e a vida, que contitui o presuposto e o imperativo de uma construção jurídica destinada a atender ao vazio da lei em contraste com as exuberâncias do social.

A existência dêsse pressuposto não autoriza por si só o processo da construção. Como foi dito atrás, é preciso atender aos apelos da realidade, e não a veleidades racionalistas. Haverá alguma exigência do real que autorize a elaboração de um novo princípio informador da responsabilidade? Nosso Código Civil é obra que parou no tempo e apoiada em uma realidade diferente da atual: os dados em que se apoiou, os fatores que a determinaram, as idéias que lhe serviram de inspiração e os senti- 
mentos que a estimularam estão certamente superados pelos acontecimentos. A um estágio puramente agrícola, que é o do Código, corresponde, agora, uma época industrial; a uma civilização de caráter ruralista sucedeu a convivência urbana; a uma convivência patriarcal sucede um sistema de vida democrático; os indivíduos incorporados em sínteses naturais estão agora à mercê dos amplos movimentos de integração política e econômica; à estabilidade financeira do país sucedeu a desvalorização da moeda; enfom, a vida moderna exige mais atividade, mais intensidade, mais diligência, mais responsabilidade. 0 edifício do Código Civil se desmorona: a legislação posterior modificou o regime da capacidade, o direito de família vê surgir uma nova categoria merecedora de proteção, a família ilegítima; no direito das cousas, ao reconhecimento e à disciplina da propriedade horizontal, novo regime de águas, florestas, caça, pesca e energia elétrica; sem falar nas transformações da propriedade ou no obsoleto regime possessório; enfim, o próprio Codigo Civil, desfigurado, atesta, êle próprio, a sua ancianidade. A realidade cresce e modifica-se e o Código, inerte, é incapaz de atender às exuberâncias de novos tempos e das novas idéias. Do fundo da alma coletiva vem um clamor exigindo novas reformas de justiça. Cumpre atendê-lo.

Sente-se, a essa altura, o pêso forte das objeções. Será lícito à doutrina e à jurisprudência enveredar por êsse caminho, em que o magistrado e o intérprete se tornam quase legislador? Não será êsse papel construtivo destinado exclusivamente à missão das assembléias? A elaboração jurídica, antes de assumir a forma de lei, é obra invisível da jurisprudência e da doutrina. Estas são, sociològicamente, os orgãos, mensuradores da sensibilidade coletiva, onde se refletem ao vivo, com tôda a grandeza e o colorido do humano, as necessidades da coletividade sofredora: uma multidão desafortunada bate às portas da justiça, tem os olhos rasos d'água. Poderá o Tribunal dizer-lhe, impassível, que nada pode fazer? Na verdade, é nas estatísticas dos tribunais que se medem as necessidades populares; se o magistrado é indeferente aos lamentos dos oprimidos, não faltarão advogados a reclamar que se abram as fontes reparadoras da 
justiça. Então a doutrina descobre o princípio em meio aos apêlos, uns frustros, outros vitoriosos, entre as decisões dos magistrados.

Examinando as reclamações, ganha a doutrina a medida sociológica da realidade; compulsando as decisões dos magistrados, busca o princípio, a idéia encoberta que é a fonte imanente dos julgados. Então é possível a tradução dessa regra em fórmula lapidar que se submete ao uso da jurisprudência. Se esta lhe reconhece a correção, apropria-se dela, ou a modifica, amplia ou restringe, para oferecê-la, límpida, ao legislador, que, agora, lhe confere o sinal da suprema eficácia da lei. Destarte, não foge à missão da doutrina e da jurisprudência o aventurarse em tais sendas; antes é esta a sua missão sociológica, a que não pode fugir, sem desmerecer os próprios créditos. A elaboração jurídica é, antes de tudo, uma elaboração social, a que se dá feição técnica apropriada; as assembléias, seu caráter político, sòmente deixam de fazer obra arbitrária quando atendem à contribuição da jurisprudência e da doutrina. Faltam-lhes, por definição, a sensibilidade para apreender as necessidades da justiça e a aptidão técnica para traduzí-las em princípios adequandos.

Outra condição da elaboração construtiva do direito é, como vimos, a sua harmonização com o direito vigente. Quer-se dizer que a construção jurídica pode ir além, suplementar e complementar, tornar-se subsidiària do sistema existente, mas não pode contrariar os preceitos.

Quais serão, então, o conteúdo e os limites dêsse novo princípio da responsabilidade?

Nosso ponto de partida é a idéia, que se encontra no art. 1519, da indenizabilidade do dano sem que tenha concorrido a culpa do ofensor. Qual o princípio informador dessa regra? Existe, no art. 160, n. II, a afirmação de que é lícito sacrificar um direito alheio para salvar cousa própria. Que princípio informa essa declaração, a não ser a conșagração do caráter sagrado do direito de propriedade? É o caráter sagrado dêsse direito, cer- 
tamente, que faz considerar lícito o que, normalmente, seria ilícito, permitindo-se o sacrifício do direito alheio. Depois, vem a segunda idéia, que é a da reparação do dano. Bem sabemos as divergências sôbre os modos de compor os prejuízos. Mas a solução verdadeira não pode ser a que obriga à reparação total, porque, dêsse modo, o estado de necessidade teria consequências puramente morais; também não pode ser a irresponsabilidade, porque então se estaria legitimando o arbítrio de se deslocar, por fato próprio, o dano que ameaça a alguém. A solução verdadeira há de fundar-se em um princípio de equidade: se o dano é necessário, deve repartir-se entre os interessados, na proporção do prejuízo sofrido por cada qual; se o prejuízo afeta apenas um patrimônio, o outro deve concorrer para a reparação na medida que o juiz determinar em cada caso. Temos, assim, destacado os dois princípios que informam um caso típico de responsabilidade objetiva: o caráter sagrado de certos direitos e as sugestões da eqüidade.

Se a lei civil protege, por essa forma, o direito de propriedade, porque não haverá de destinar igual proteção a direitos sem dúvida mais sagrados, como a vida, a integridade corporal, a honra, a subsistência? Se, por outro lado, a lei submete àquele que se encontra em estado de necessidade à obrigação de reparar o dano, porque não haverá de obrigar também aquêle que, sem ter de praticar atos indispensáveis, causa prejuízo a outrem?Quem merece melhor a benevolência da lei: aquêle que, forçado pela necessidade, causa dano a outrem, ou aquele que, sem o império de circunstâncias irremovíveis, dá causa a prejuízos a outrem? Sem dúvida, deve preferir-se o primeiro, porque o último, provàvelmente, teria evitado o prejuízo, pondo mais diligência no exercício de suas atividades. Pois se o agente em estado de necessidade é obrigado a reparar o dano, não há razão para excluir dessa obrigação quem não está nessa situação.

Agora, é necessário concluir. E, à guisa de rápida conclusão, diremos o seguinte:

1 - Entendemos que a teoria da culpa em matéria de res- 
ponsabilidade civil é o resultado de uma falsa colocação do problema da vontade na reparação dos danos, e que, a exigir o elemento culposo na caracterização do ilícito, deve sempre considerar-se existente a responsabilidade, salvo ao ofensor a demonstração de um procedimento irrepreensível. Ganha com isso a moralidade social, pois que todos diligenciarão em exercer com mais prudência os seus direitos.

2 - Pensamos que o estado atual do nosso direito permite e está a exigir a construção de uma teoria objetiva da responsabilidade civil, a qual terá um lugar próprio independente, mas subsidiário, e que tem como fundamento o caráter altamente sagrado de certos direitos - a vida, a honra e o direito à subsistência.

3 - Êsse tipo de responsabilidade, nítidamente objetiva, mas que não entra em conflito com o sistema de nosso direito civil, mas, antes, nêle se embasa, ditingue-se do princípio da responsabilidade subjetiva quanto aos limites da reparação: está última é a mais ampla possível, - a de que se trata é limitada e proporcional às necessidades da vítima e às possibilidades do agente.

4 - Restaria o problema das garantias; mas, fugindo a questão ao objetivo específico dêste estudo, diremos só que a solução está em se intituírem fundos de garantia, a exemplo do que acontece, há largos anos, no mundo anglo-americano, e, de certo tempo a esta parte, na Suiça e na França. 